\title{
ENVIRONMENTAL EFFECTS ON POTATO GROWERS RESULTING FROM THE IMPLEMENTATION OF THE CONVENTION ON THE EGYPTIAN -EUROPEAN PARTNERSHIP
}

(Received: 4. 4. 2011)

\author{
By \\ A. A . Azam and M. S. Mohamed* \\ Department of Rural Sociology and Agricultural Extension, Faculty of Agriculture, Cairo University, and \\ *Agricultural Extension and Rural Development Research Institute, Agriculture Research Center, \\ Giza, Egypt
}

\begin{abstract}
The present study aimed at identifying the knowledge level of potato farmers regarding export conditions of potatoes to the European Union (EU), to determine the differences between the knowledge degrees of the farmers in two villages to identify farmer opinions regarding the environmental effects of the agricultural part of the Egyptian-European convention, and to identify the problems facing farmers since the implementation of the Egyptian-European convention.

The study was conducted in the village of "Sayedna Solomon" in Nobariya area, Beharia Governorate as one of the largest areas inside the Pest Free Area (PFA), and the village of "Talia", Menofia Governorate as one of the largest areas outside the Pest Free Area (PFA) . A random sample of 50 farmers was chosen from Sayedna Solomon village and 100 farmers from Talia village.

Data were collected through personal interviews with respondents by using pre-tested questionnaires prepared specifically to achieve the study objectives.

Frequencies, percentages, means, and standard deviations, in addition to "t" test were used to present and analysis of the obtained data.

\section{The most important results of the study were}

1-There was significant differences at 0.05 level between farmers' level of knowledge in the two studied villages regarding the export conditions of potatoes to the (EU).

2- There was an increase in the negative environmental effects on small farmers resulting from applying the Egyptian-European convention as the investigated farmers expressed, and the differences between the two studied villages were significant at 0.01 level.

3- There were main problems facing small farmers in the "Sayedna Solomon" village concerning the market of the crop locally, the low export prices, and the shortage of irrigation water in the summer, while the main problems in "Talia "village were concerning the lack of input supply and the high prices of the inputs, the irrigation problem, and the problem of marketing the crop locally.
\end{abstract}

Key words : convention, environmental effects, implementation, partnership, potato growers.

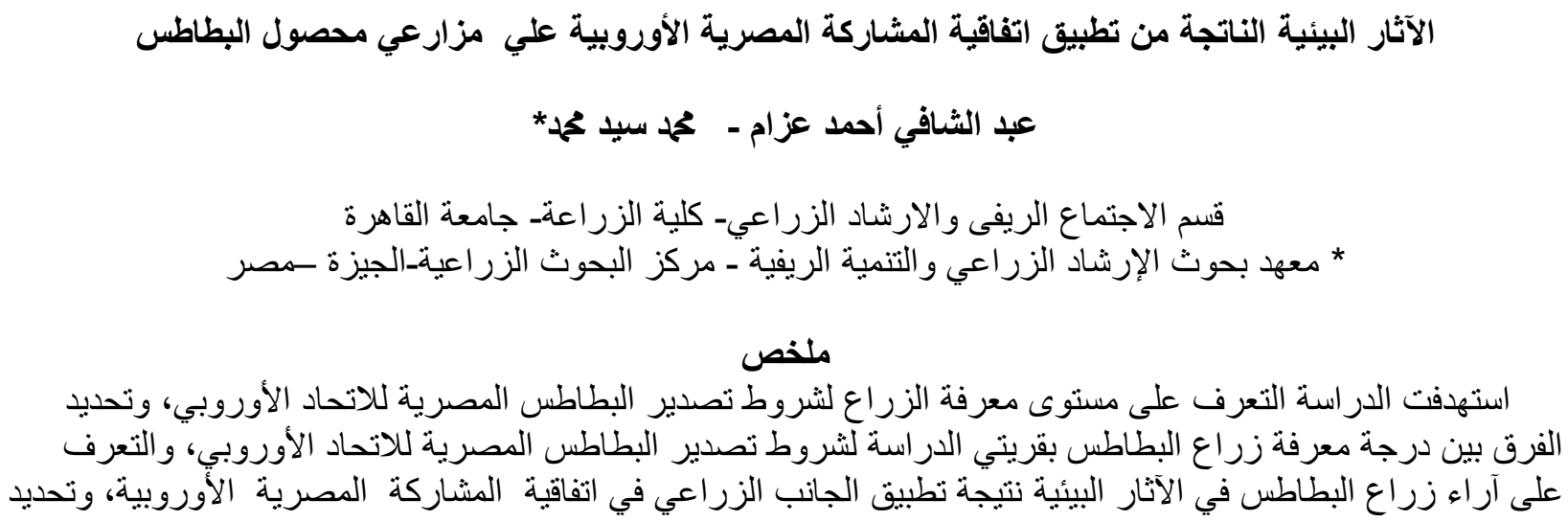


الفرق بين الدرجات المعبرة عن آراء زراع البطاطس للآثار البيئية لتطبيق الجانب الزراعي في اتفاقية المشاركة المصرية

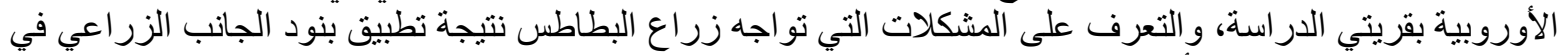
اتفاقية المشاركة المصرية الأوروبية.

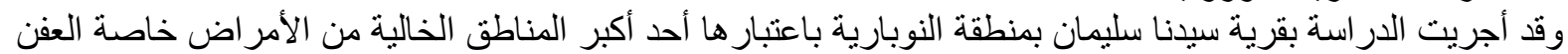

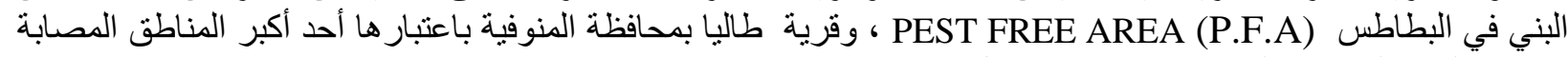

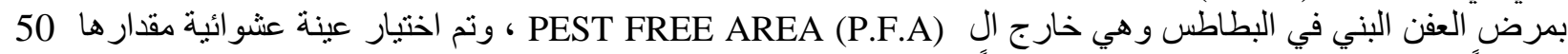

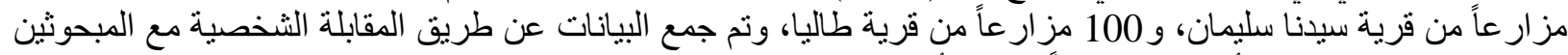

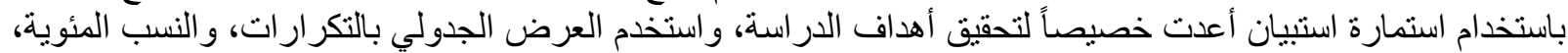

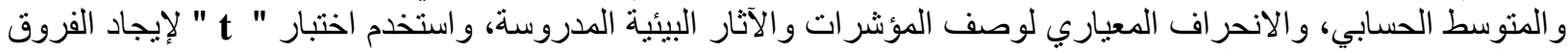
بين المجمو عتين (منطقتي الدراسة).

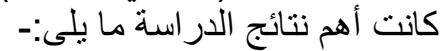
1 - توجد فروق معنوية عند مستوى 0.05 بين مستوى معرفة المزار عين في القرينين بشروط تصدير البطاطس إلى الاتحاد الأوروبي.

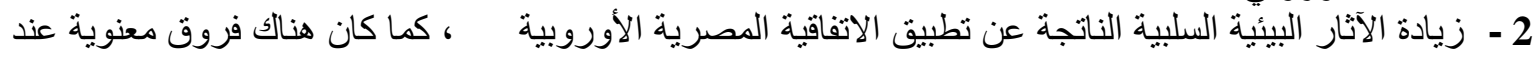

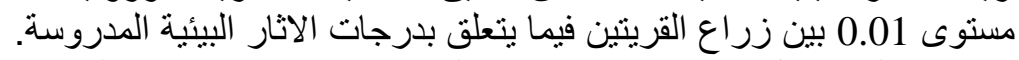

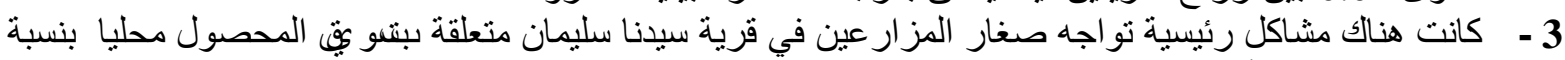

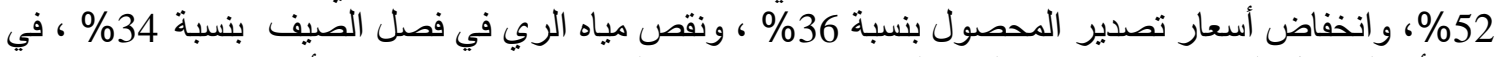

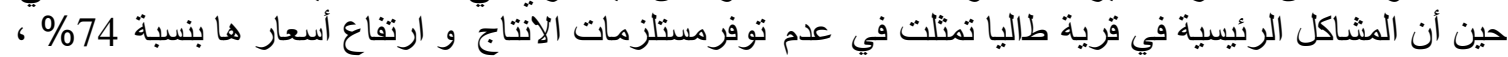

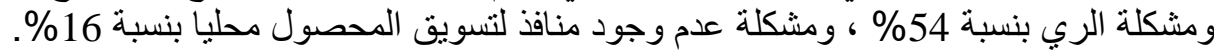

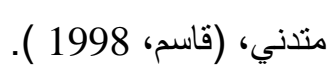

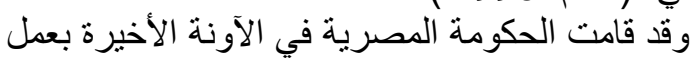

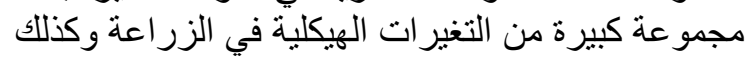

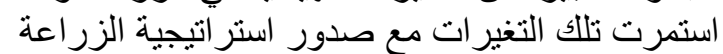

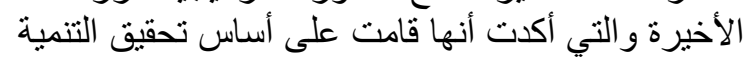

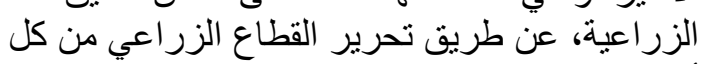

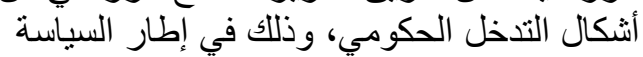

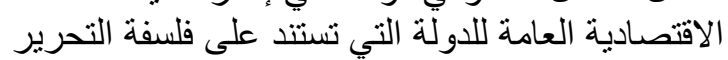

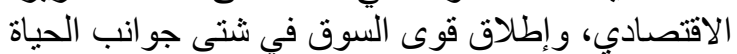
الاقتصادية.

تهدف هذه السياسة كما ذكرت الحكومة المصرية آنذاكلك

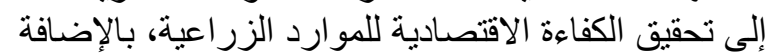

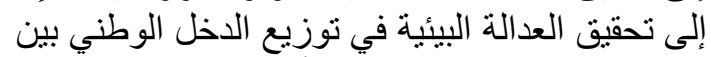

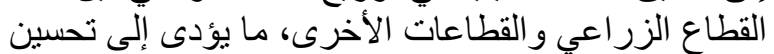
مستوى معيشة الفلاحين.

قامت هذه الاستر اتيجية في المقام الأول على مبلى مبدأ

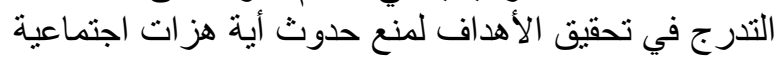

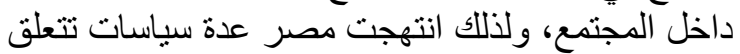
بالنو احي السعرية و التسويقية والنية التمويلية و الدعم و التجارة الخارجية، (استر اتيجية وز ارة الزر العة التئة 2007- 2017).

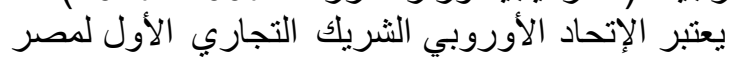

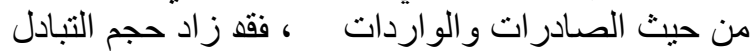

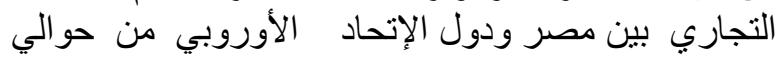
11.5 مليار يورو في عام 2004 إلى 2004 إلى 13.3 مليار يورو في في

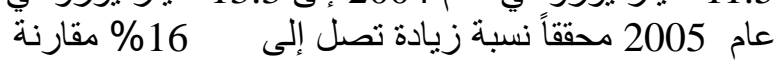

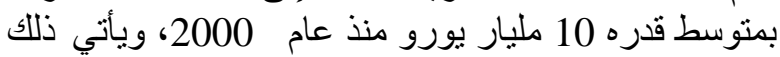

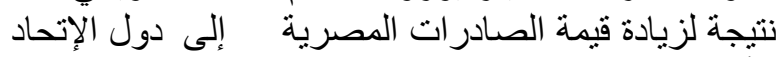

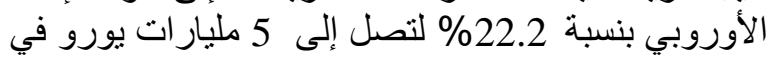
عام 2005 مقابل 4.1 مليار يورو في عام 222. 2004، وفي

\section{1- الزقاعة و المشكلة البحثية}

يعتبر القطاع الزر اعي فى مصر من ألهم القئلة القطاعات

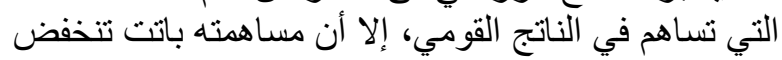

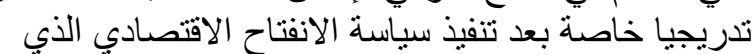

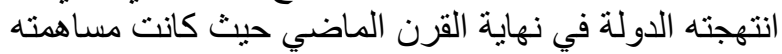

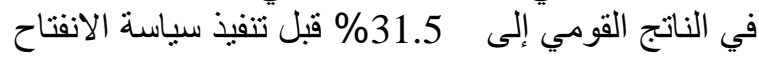

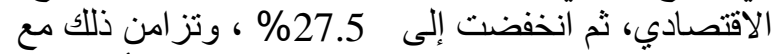

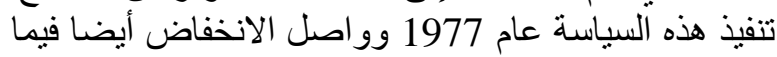

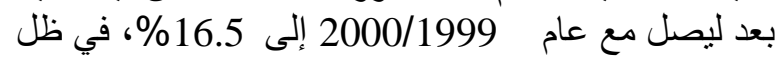

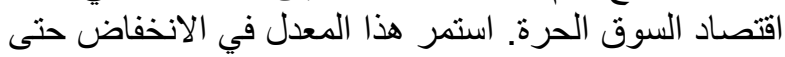

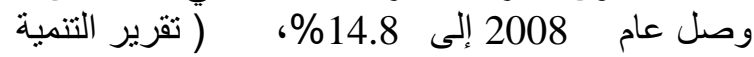

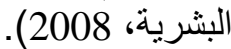

يمثل تقدم الزر اعة هدفا تسعى الحكومة إلى تحقيقه،

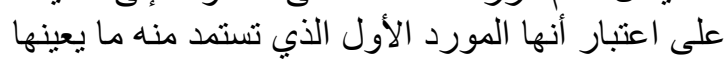

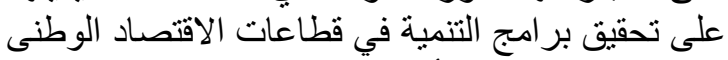

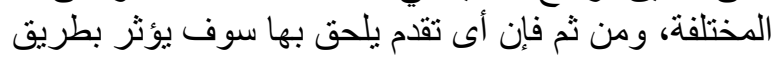

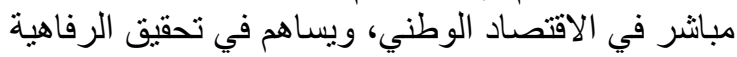
لكل المو آطنين عامة والفئ الفلاحين خاصة.

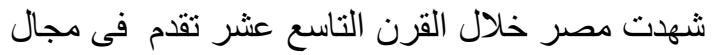

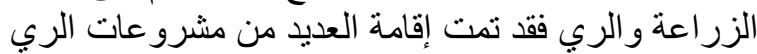

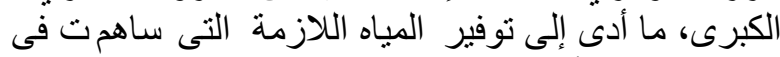

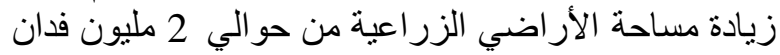

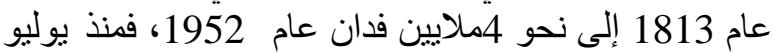

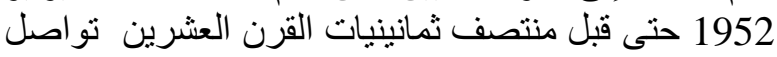

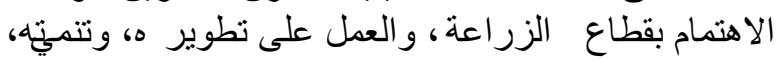

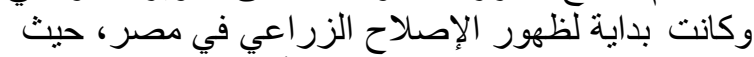

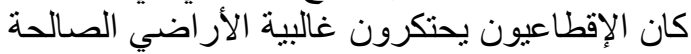

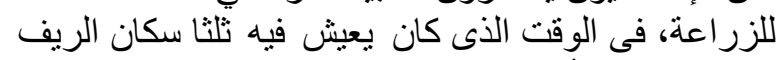

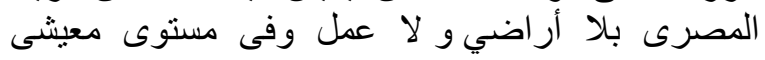


الى المز ارعين حيث التطبيق العملي للافكار و المستحدثات

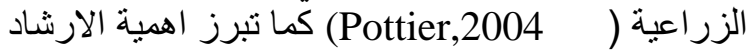
الزراعي في التعليم و الربط بين نواتج البحوث الزئ الزر اعبة الزية

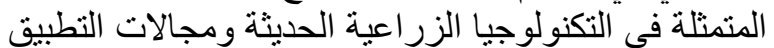
في الريف و اقناع وتدريب الزئر الزراع بأهية هذه التقنيات

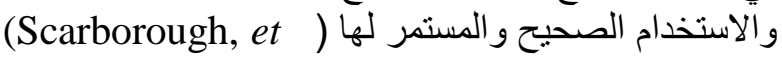
al., 1997).

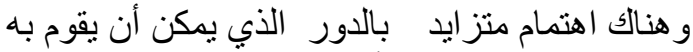

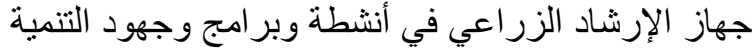

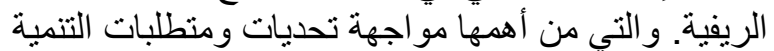

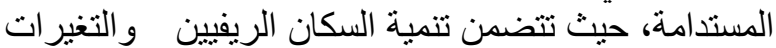

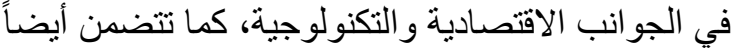
التغير ات في الأبنية الاجتماعية و السياسية لبيئتهم المحلية.

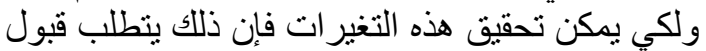

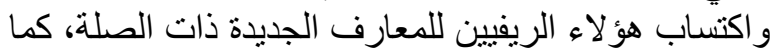

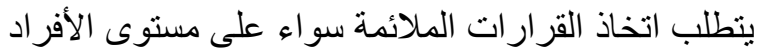

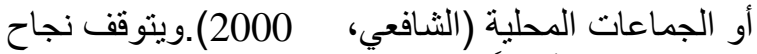

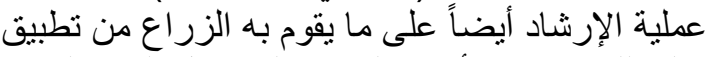

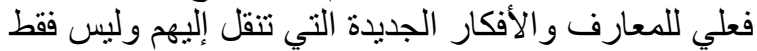

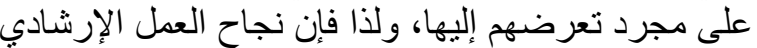

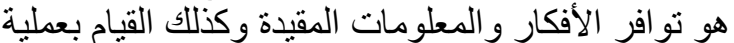

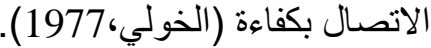

إن كل هذا يطرح العديد من التساؤ لات البحثية الملحة

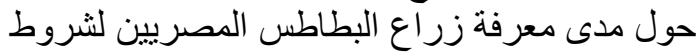

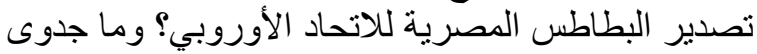

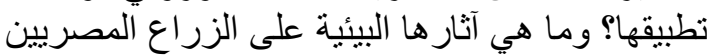
و أسر هم وبيئتهم المحلية: ولئه كل هذا دعي إلي ضرورة إلية إجر اء تللك الدر اسة من أجل

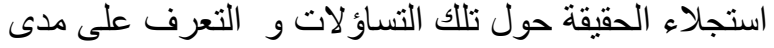

معرفة زر اع البطاطس لبنود اتفاقية المشاركة المصنية التصرية

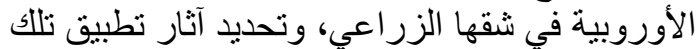

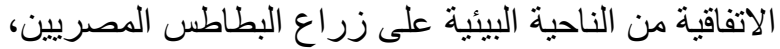

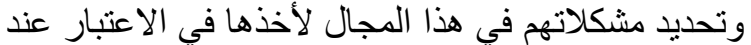
التوقيع على مثل هذه الاتفاقيات، أو عند التخطيط لتنفيذ التيذ

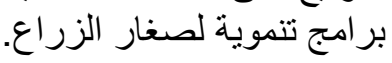

\section{2- 2- أهداف الرحث}

اتساقاً مع مشكلة الدراسة السابق عرضها الهـا فقد تم صياغة أهداف البحث كما يلي: التئ

1 - التعرف على مستوى معرفة الزر اعلى لثروط تصدير البطاطس المصرية للاتحاد الأوروبي.

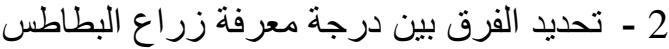

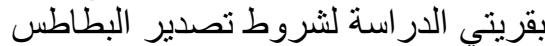
المصرية للاتحاد الأوروبي.

3 - التعرف على الآثار البيئية لزر الزئية البطاطس نتيجة

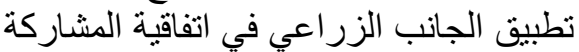

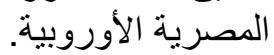

4 - تحديد الفرق بين الدرجات الأروبة المعبرة عن الآثار البيئية لزراع البطاطس بقريتي الدراسة نتيجة الأنار
نفس الوقت زادت قيمة الو اردات المصرية من حو الي 7.3 مليار يورو في عام 2004 إلى 8.2 مليار يورو في عام الم المي 2005

كما بستحوذ الإتحاد الأوروبي على 28\% من حجم الإرجم

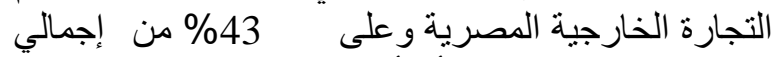

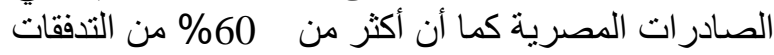
الاستثمارية المباشرة تأتى من دول الإتحاد الأوروبي سني سنويا.

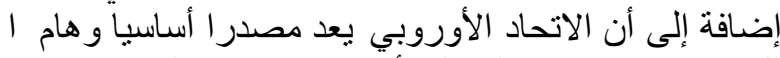
للإساعدات الإنمائية التي لها أثر كبير في عملية الإصلاح

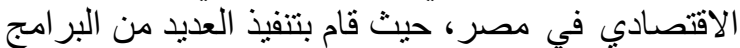
الإنمائية، (مركز الأرض لحقوق الإنسان 2008).

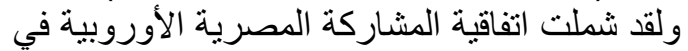

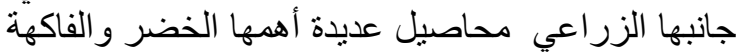

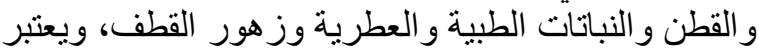

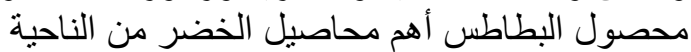

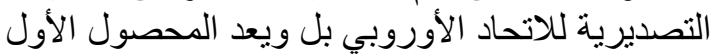
تصديريا مقارنة بكافة المحاصيل الزيل الزراعية. تنتشر زر اعة البطاطس في محافظات البطات البحيرة و المنوفية

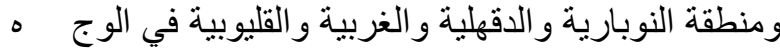

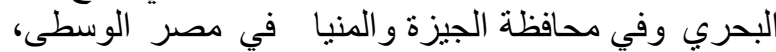

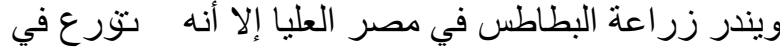

مساحات متفرقة.

وتبلغ المساحة التي تزر ع بالبطاطس في مصر حو الي

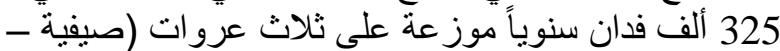

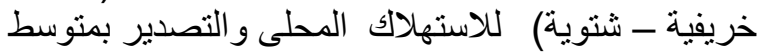

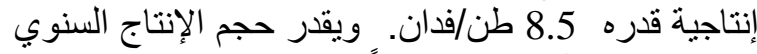

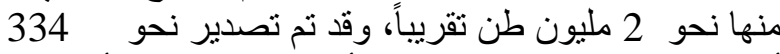

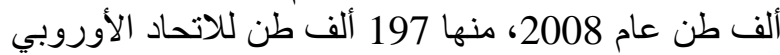

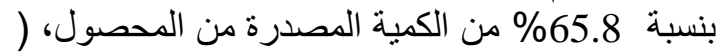
الحجر الزراعي المصري، 2008، بئهة التيانات غير منشورة).

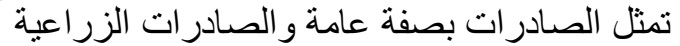

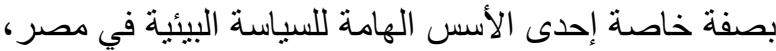
حيث ينظر إليها على أنها قاطرة التنمية وبأن إحباءها سيؤدي إلى النجاح في التغلب على النى معظم المشاكل البيأئية

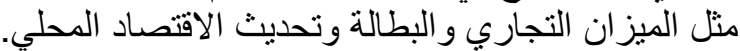

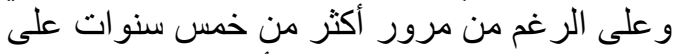

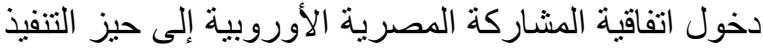

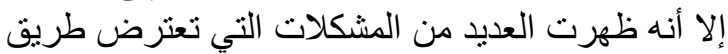

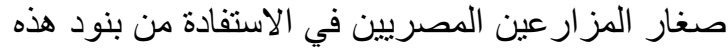

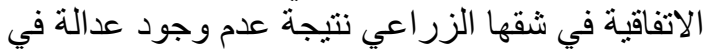

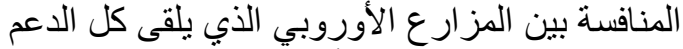
و الرعاية من الحكومات الأوروبية في كافة مر الزية الاحل الإنتاج

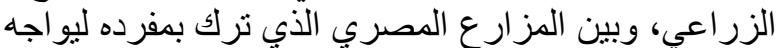

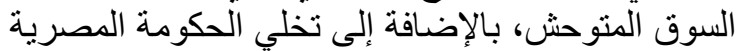

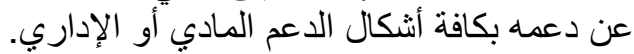

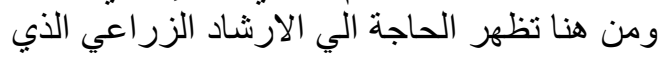

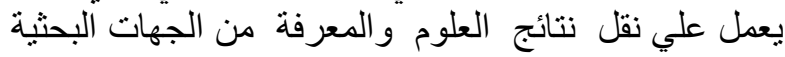


منهم بالطريقة العشو ائية بلغت 100 مز ار عاً تمثل حوالي البئ \% 32 من إجمالي شاملة زراع البطة البطاطس بالقرية.

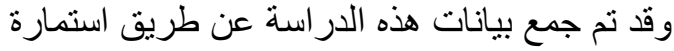

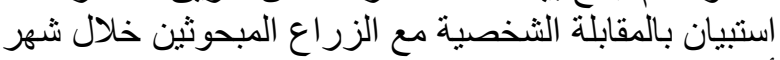

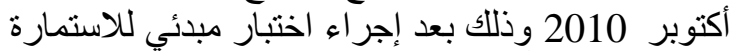

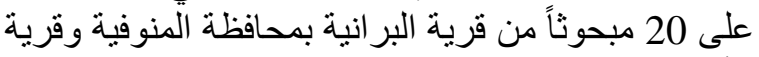

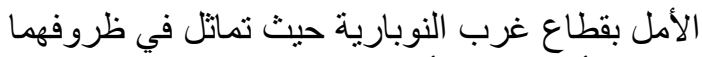

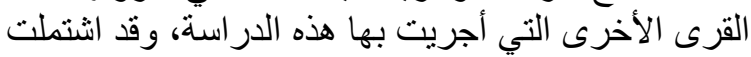

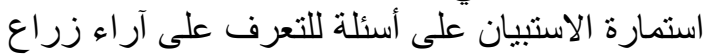

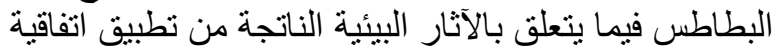

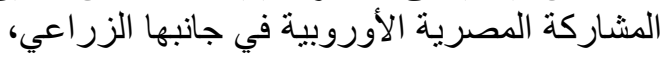

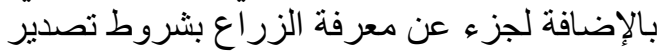

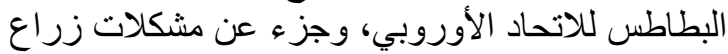
البطاطس بمنطقتي الدر اسة. 2-3-3-التعريف الإجرائي 2-1-3-3-3 الآثار البيئية

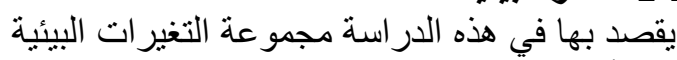

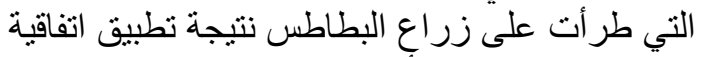

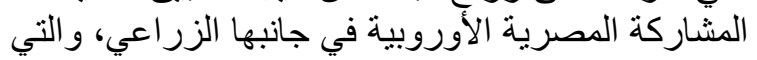

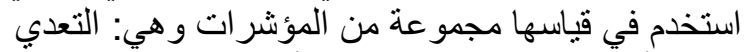

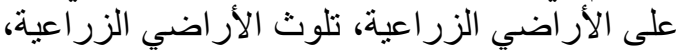
المحافظة على البيئة. 3-3-3-3-3 المعالجة الكمية للبيانات الباتة 1-3-3-3-3 الآثار البيئية بعد تطبيق الاتفاقية

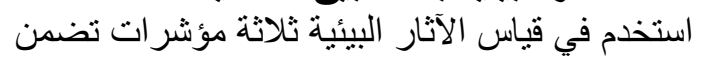

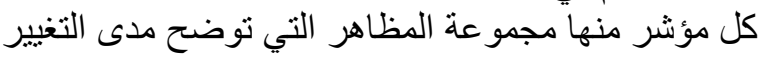

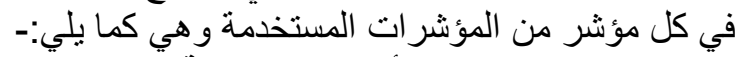
1-1-3-3 - التعدي على الأراضي الزراعية التئية

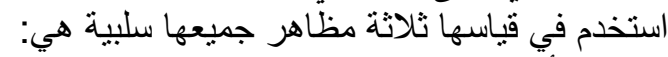

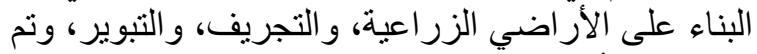

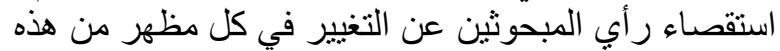

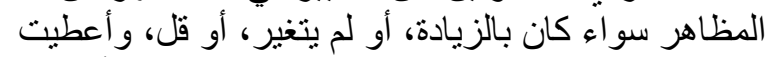

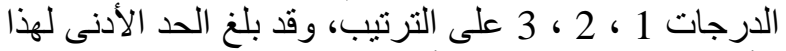

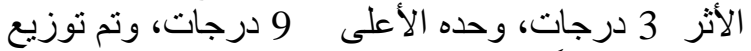
المبحوثين وفقاً لر أيهم في هذا الألثر الأثر إلى ثلاث فئات هي:

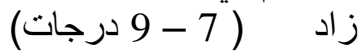

$$
\begin{aligned}
& \text { لم يتغير ( } 5 \text { - } 6 \text { درجات) } \\
& \text { قلم ل }
\end{aligned}
$$$$
\text { 2-1-3-3 - تلوث المجاري المائية }
$$

استخدم في قياسها ثلاثة مظاهر جميعها سلئية البية هي:

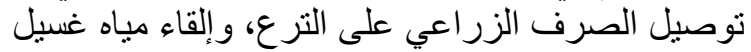

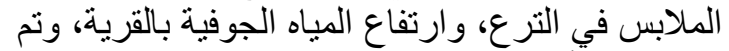

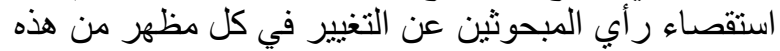
المظاهر سواء كان بالزيادة، أو لم يتغير، أو قل، التين و أعطيت

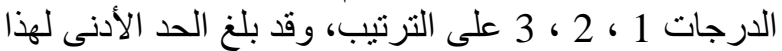

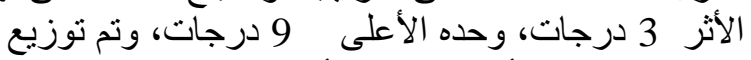
المبحوثين وفقا لر أيهم في هذا الأثر إلى ثناث فئات
تطبيق الجانب الزر اعي في اتفاقية المشاركة المصرية الأوروبية. 5 - التعرف على المشكلات التي تو اجه صغار الزئل

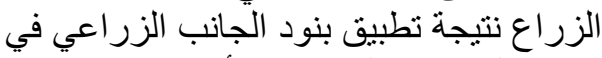
اتفاقية المشاركة المصرية الأوروبية.

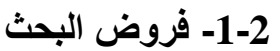

1 - توجد فروق معنوية بين درجات معرفة الزر البماع

بقريتي الدراسة لثروط تصدئ لتربير البطاطس المصرية للاتحاد الأوروبي.

2 - نوجد فروق معنوية في الدرجاد الأربات المعبرة عن آراء

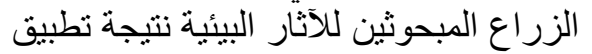

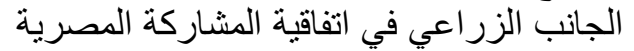
الأوروبية بقريتي الدراسية فئان.

وقد تم اختبار هذه الفروض في صورية صورتها الصفرية.

\section{3- الطريقة البحثية}

\section{1-3-3 منطقة البحث}

اختيرت منطقة النوبارية باعتبار ها أحد أكبر المناطق الخالية من الأمر اض خاصة العفن البني في البطاطس البرس البناطي PEST FREE AREA (P.F.A)

التصدير للاتحاد الأوروبي، كذللك فقد اختيرت محافظة الهئ

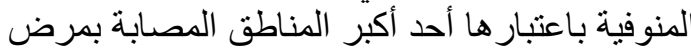

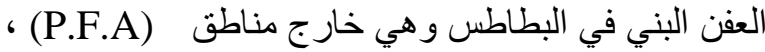

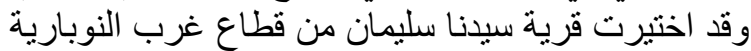

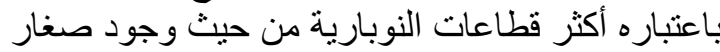

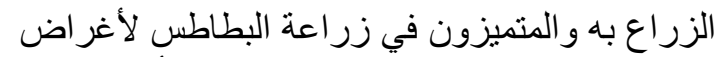

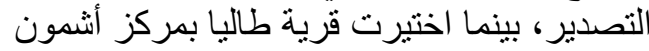

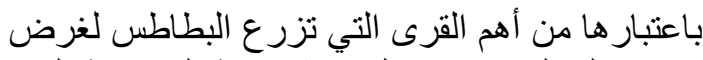

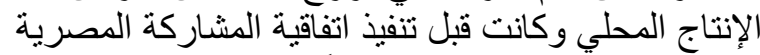

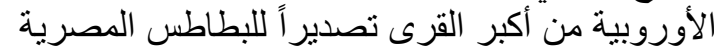
لماملة البحاد الأوروبي. شاملة البحث و وعينته

اقتصرت الدر اسة على اختيار قرينين أحداهما تقع

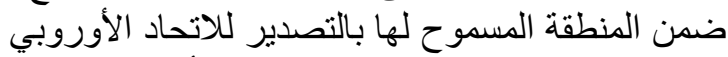

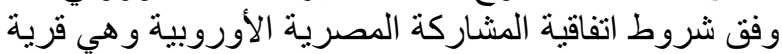

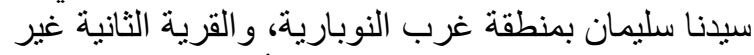

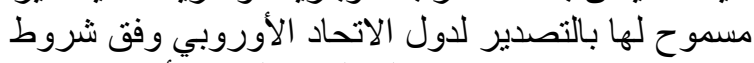

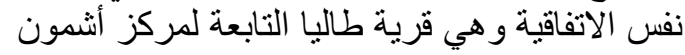
بمحافظة المنوفية حيث يتم استخدام المحصول للاستية لاستهلاك المحلي، وقد بلغ عدد زر اع البطاطس في موسم البن

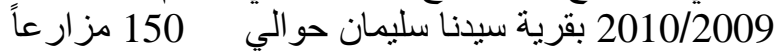
يمتلون شاملة زر اع البطاطس بغرض التصدير بالئانيا بالقرية، وتم اختيار عينة ممنلة منهم بالطريقة العشو ائية بلغت

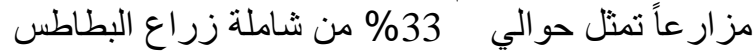

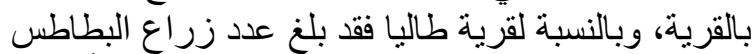

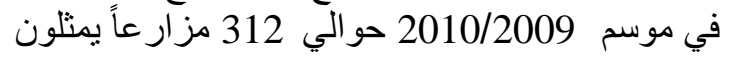
شاملة زراعة البطاطس بالقرية، وُتم اختيار عينة مدثلة 
مستويات هي: لا يعرف(حتى

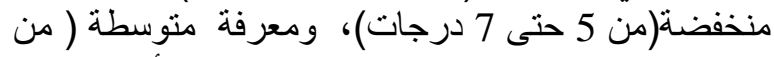

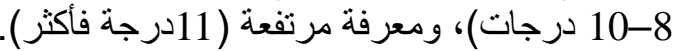

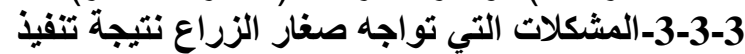
اتفاقية المشتاركة المصرية الأوروبية التراعية

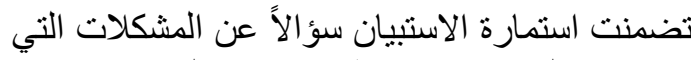

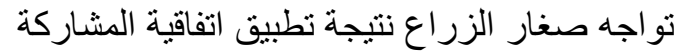

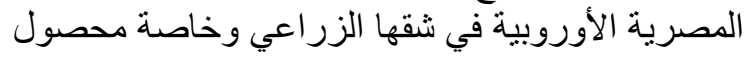
البطاطس وقد تم التعبير عنها بطريقة ولفية وصفية باستخدام التكر ار ات و النسب المئوية. أدوات التحليل الإحصائي

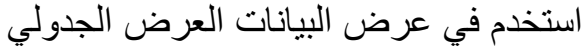

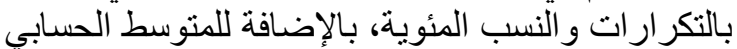
و الانحر اف المعياري، كذلك استخدم اختبار " الفروق بين المجمو عنين( منطقتي الدراسة).

\section{4- النتائج ومناقشتها \\ 1-4- مستوى معرفة زراع البطاطس بشروط التصدير ل اللاتحاد الأوروبي.}

أظهرت النتائج الواردة بالجدول رقم ( 1 1) انخفاض في

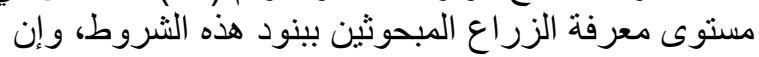

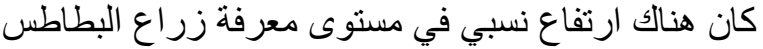

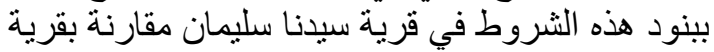

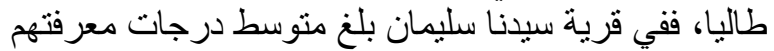
بشروط التصدير للاتحاد الأوروبي 8.04 درجة 8.04 درجة بنسبة

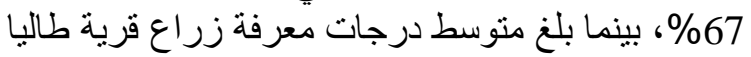

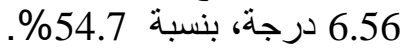

جدول (1): توزيع المبحوثين بقرى الاراسة وفقاً لمتوسط درجة معرفتهم بشروط التصدير للاتحاد الأوروبي ونسبتها.

\begin{tabular}{|c|c|c|}
\hline$* \%$ & الدرجة المتوسطة & الهتوسط \\
\hline 67 & 8.04 & قرية سيدنا سليمان \\
\hline 54.7 & 6.56 & قرية طاليا \\
\hline
\end{tabular}

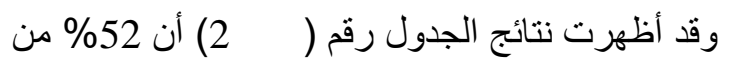

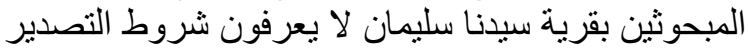

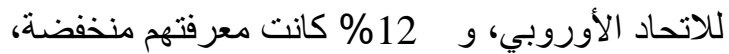

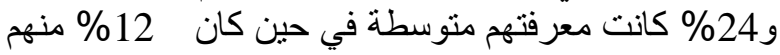

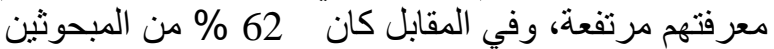

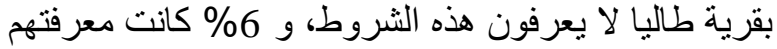
منخفضة، و 6\% \% كانت معرفتهم منوسطة في حين كان كان 26\% منهم معرفتهم مرتفعة.

2-4- الفرق بين درجة معرفة زراع البطاطس لثرة لثروط

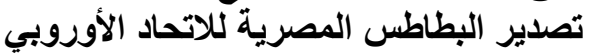

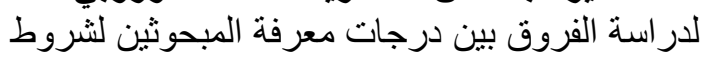
تصدير البطاطس المصرية للاتحاد الأوروبي في كل من لئن

$$
\begin{aligned}
& \text { زاد ( } 7 \text { - } 9 \text { درجات) } \\
& \text { لم يتغير ( } 5 \text { - } 6 \text { درجات) }
\end{aligned}
$$

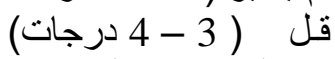

$$
\begin{aligned}
& \text {-3-1-3-3 المحافظة على البيئة }
\end{aligned}
$$

استخدم في قياسها خمسة مظاهر المبة إحداها سلبي هي:

كثرة استخدام الأسمدة و المبيدات، وأربعة مظاهية إنهر إيجابية.

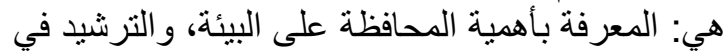

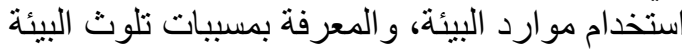

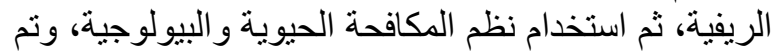

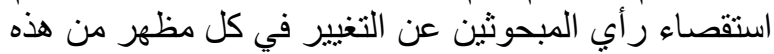
المظاهر سواء كان بالزيادة، أو لم يتغير، أو أل قل، و أعطيت الدرجات 1 ، 2 ، 3 على الترتيب في حالة التئ المظاهر

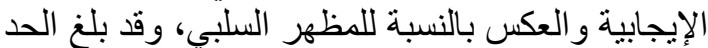

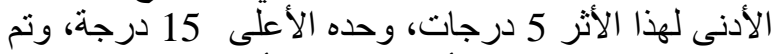

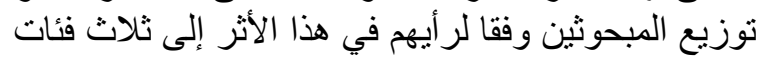

$$
\begin{aligned}
& \text { زاد ( } 12 \text { - } 15 \text { درجة) } \\
& \text { لم يتغير ( } 9 \text { - } 11 \text { د درجة) } \\
& \text { قل ( } 5 \text { - } 8 \text { درجات) }
\end{aligned}
$$

وللحصول على الدرجة الكلية المعبرة عن الآثار

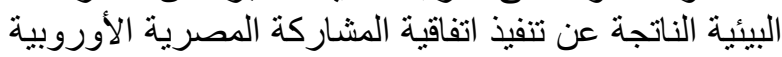

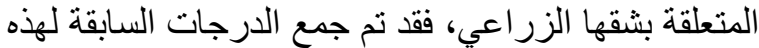

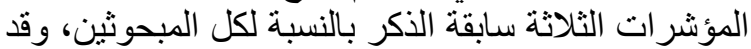

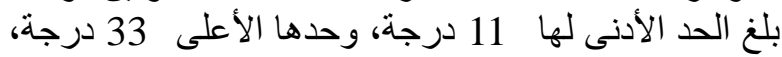
وتم توزيع المبحوثين وفقا لر أيهم في الآثار البيئية الناتجة الإنة من تنفيذ اتفاقية المشاركة المصرية الأوروبية الأنار لاينية إلى ثلاث

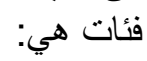

$$
\text { - }
$$

2-3-3-3عرفة الزراع بشروط تصدير البطاطس المصرية للاتحاد الأوروبي.

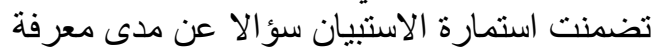
المبحوثين لنروط تصدير البطاطس المصنية المبرية للاتحاد

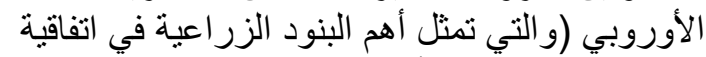

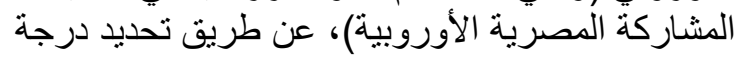

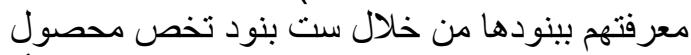

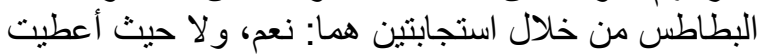

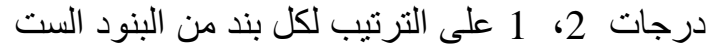

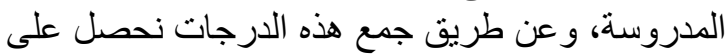

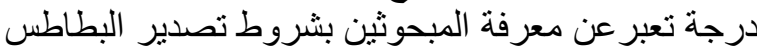

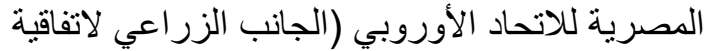

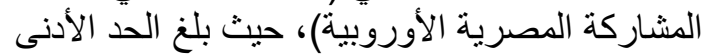

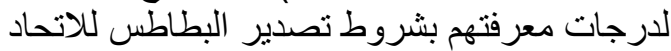

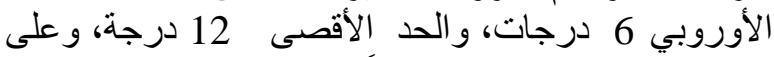

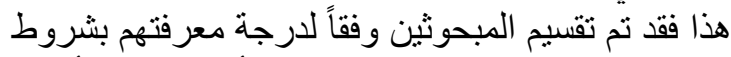
تصدير البطاطس المصرية للاتحاد الأوروبي إلى أربعة لفئة 
وعند در اسة هذه الآثار البيئية من خلال المظاهر التي

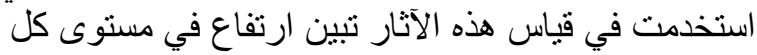

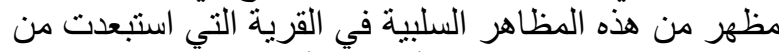

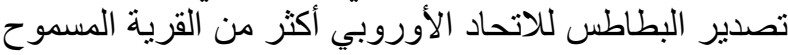

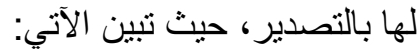

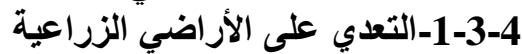

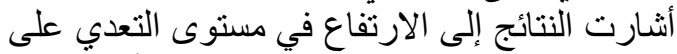

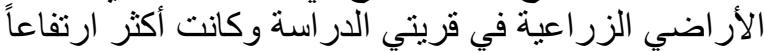

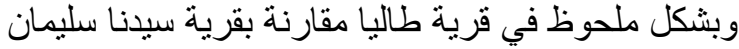

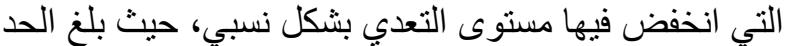

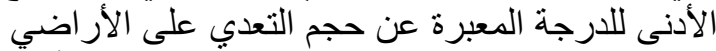

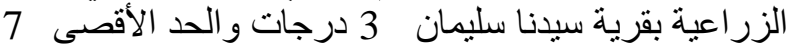
درجات بمتوسط حسابي قدره معياري قدره 0.863 ، في حين بلغ الحد الأدنى للارجة

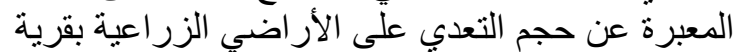

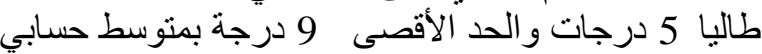
قدره 7.02 درجة و انحر اف معياري قدره 1.204.

جدول (3): توزيع المبحوثين وفقا لمستوى الآثار البيئية نتيجة تنفيذ اتفاقية المثاركة المصرية الأوروبية المئية بقريتي نيجية

الاراسة.

\begin{tabular}{|c|c|c|c|c|}
\hline \multicolumn{2}{|c|}{ قرية طاليا } & \multicolumn{2}{|c|}{ قرية سيدنا سليمان } & \multirow{2}{*}{ الآثار البيئية القرية } \\
\hline$\%$ & عدد & $\%$ & عدد & \\
\hline - & - & 68 & 34 & آثنار منخفضة \\
\hline 44 & 44 & 32 & 16 & آثار متوسطة \\
\hline 56 & 56 & - & - & آثار مرتفعة \\
\hline 100 & 100 & 100 & 50 & \\
\hline
\end{tabular}

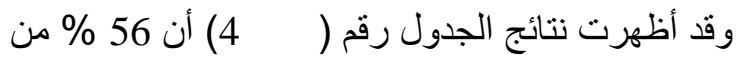
المبحوثين بقرية سيدنا سليمان كانو ا ذوبي مستول التوى منخفض

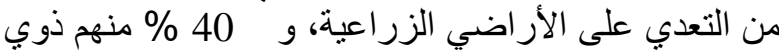

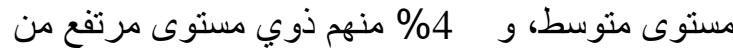

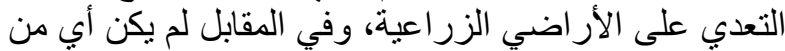

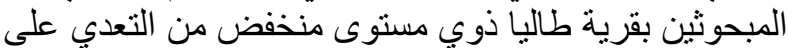

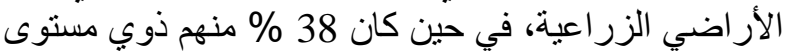

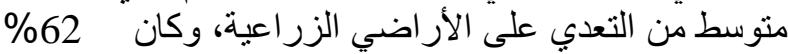

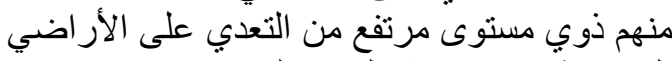

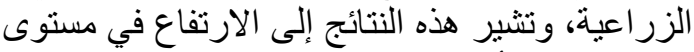

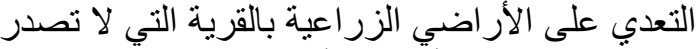

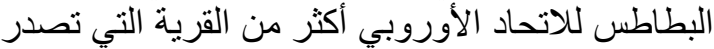

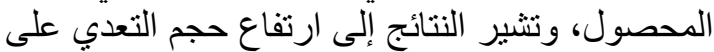
الأراضي الزر اعية في المستوى الأعلى في قرية العية طاليا أكثر

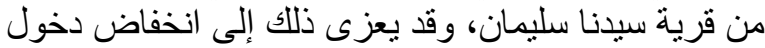

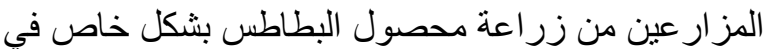
القرى غير المصدرة للمحصول، بالإضافة للارتفاع الجناع الجنوني

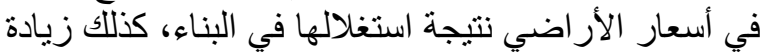

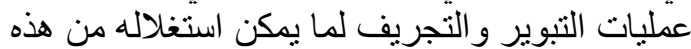

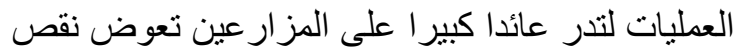

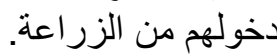

قريتي الدر اسة استخدم اختبار ( t ) )، حيث أظهرت النتائج أن

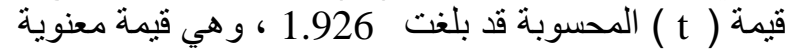

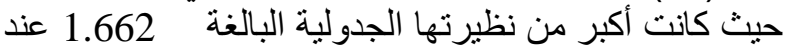

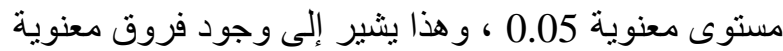

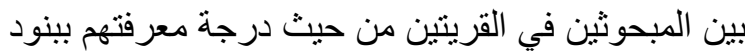
شروط تصدير البطاطس المصنية من فئن للاتحاد الأوروبي. وقد تكون هذه النتيجة منطقية نتيجة ارتباط قرية سيدان الأنيا

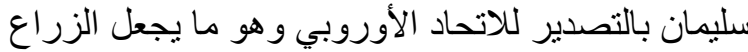

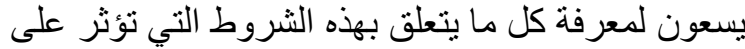

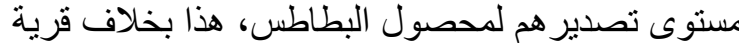
طاليا التي حرمت من تصدير المحصول لتمبل للاتحاد الأوروبي

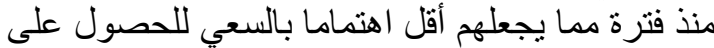
معلومات عن هذه الشروط.

3-4- الآثار البيئية الناتجة من تطبيق اتفاقية المشاركة

جدول ( 2): توزيع المبحوثين وفقاً لمستوى معر فتهم لثروط تصدير البطاطس المصرية للاتحاد الأوروبي.

\begin{tabular}{|c|c|c|c|c|}
\hline \multicolumn{2}{|c|}{ قرية طاليا } & \multicolumn{2}{|c|}{ قرية سيدنان } & \multirow{2}{*}{ مستوى المعرفة القرية } \\
\hline$\%$ & عدد & $\%$ & عدد & \\
\hline 62 & 62 & 52 & 26 & لا يعرف \\
\hline 6 & 6 & 12 & 6 & معرفة منخفضة \\
\hline 6 & 6 & 24 & 12 & معرفة متوسطة \\
\hline 26 & 26 & 12 & 6 & معرفة مرتفعة \\
\hline 100 & 100 & 100 & 50 & الإجمالي \\
\hline
\end{tabular}

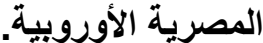

أظهرت النتائج زيادة في مستوى الآثار البيائية على البئ

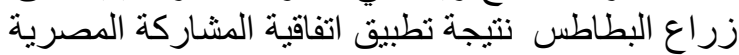

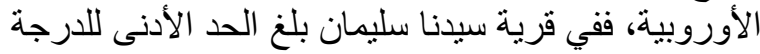

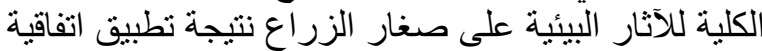

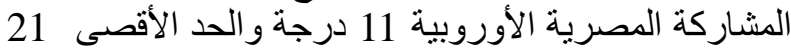
درجة بمتوسط حسابي قدره

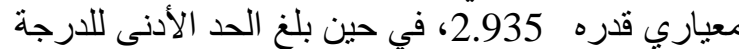

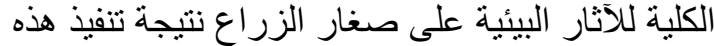

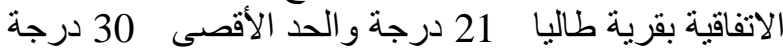
بمتوسط حسابي قدره 25.36 درجة و انحر اف معياري لافي قدره 2.648

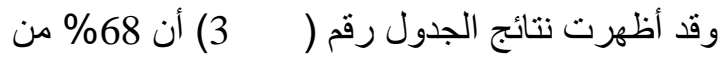

المبحوثين بقرية سيدنا سليمان كانوا ذانوي آثنار بيائية

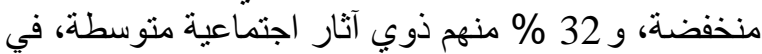

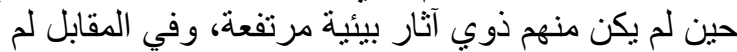

يكن أي من المبحوثين بقرية طاليا ذوي آثار آجتماعية آناعية

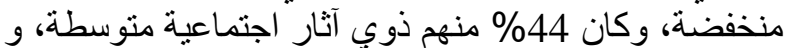

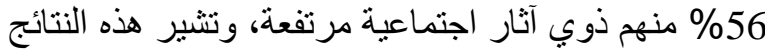
إلى ارتفاع في مستوى الآثار البيئية السلبية نتيجة تطبية تبنيق اتفاقية المشاركة المصرية الأوروبية في قرية طاليا أكثر من الئنية

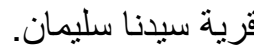


ارتفاع مستوى دخول الزراع نتيجة تصدير محصول

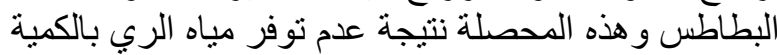

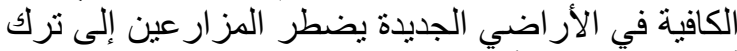

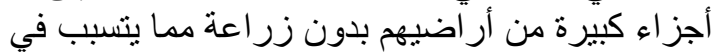

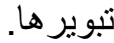

2-3-4-3 تلوث المجاري المائية بالقرية

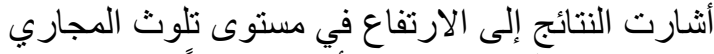

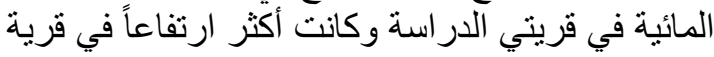

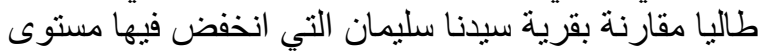

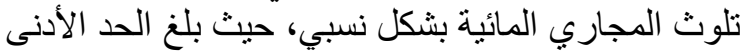
للارجة المعبرة عن حجم تلوث المجائة المجاري المائية بقرية سيدنا

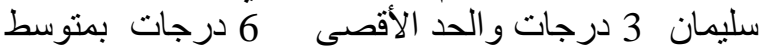

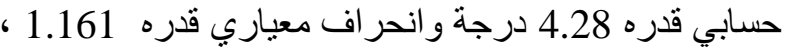

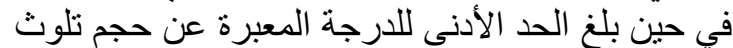

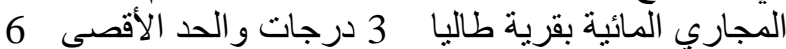
درجات بمتوسط حسابي قدره

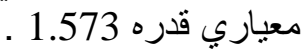

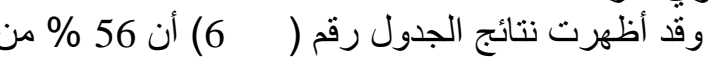

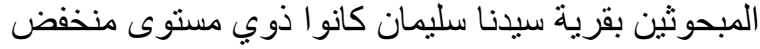

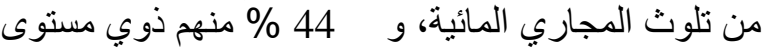

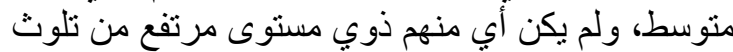

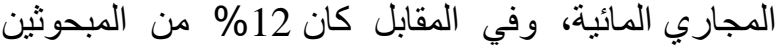

جدول ( 4): توزيع المبحوثين بقريتى الدراسة وفقا

لمستوى التعدي على الأراضي الزراعية.

\begin{tabular}{|c|c|c|c|c|}
\hline \multicolumn{2}{|c|}{ قرية طاليا } & \multicolumn{2}{|c|}{ قرية سيدنا سليمان } & 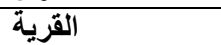 \\
\hline$\%$ & عدد & $\%$ & 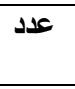 & الأتعدي على الزراعية \\
\hline- & - & 56 & 28 & تعلي منخفض \\
\hline 38 & 38 & 40 & 20 & تعدي متوسط \\
\hline 62 & 62 & 4 & 2 & تعلي مرتفع \\
\hline 100 & 100 & 100 & 50 & الإجمالي \\
\hline
\end{tabular}

وبدر اسة المظاهر التي استخدمت لقياس و المقارنة بين

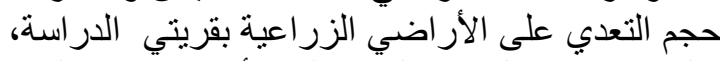

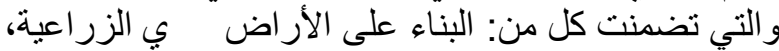

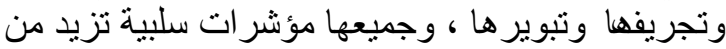

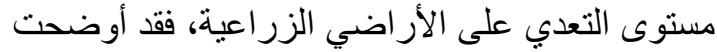

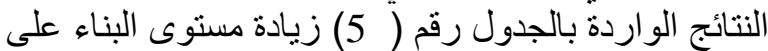

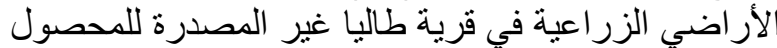
بنسبة 96 \% منذ تطبيق اتفاقية المشاركة المصرية

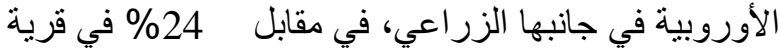

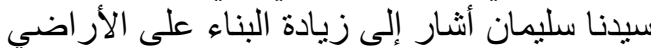

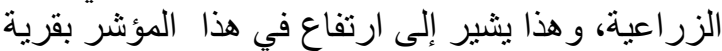
طاليا مقارنة بقرية سيدنا سليمان.

جذول (5): توزيع المبحوثين بقريتي الدراسة وفقا لمظاهر قياس التعدي على الأراضي الزراعية.

\begin{tabular}{|c|c|c|c|c|c|c|c|c|c|c|c|c|}
\hline \multicolumn{6}{|c|}{ قرية طاليا } & \multicolumn{6}{|c|}{ قرية سيدنا سليمان } & \multirow{3}{*}{ مظاهر البطالة القرية } \\
\hline \multicolumn{2}{|c|}{ قل } & \multicolumn{2}{|c|}{ لم يتغير } & \multicolumn{2}{|c|}{ زاد } & \multicolumn{2}{|c|}{ 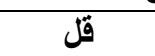 } & \multicolumn{2}{|c|}{ لم يتغير } & \multicolumn{2}{|c|}{ زاد } & \\
\hline$\%$ & عدد & $\%$ & عدد & $\%$ & عدد & $\%$ & عدد & $\%$ & عدد & $\%$ & عدد & \\
\hline- & - & 4 & 4 & 96 & 96 & 32 & 16 & 44 & 22 & 24 & 12 & البناء على الأراضي الزراعية \\
\hline 16 & 16 & 78 & 78 & 8 & 8 & 50 & 25 & 44 & 22 & 6 & 3 & تجريف الأر اضي الزّراعية \\
\hline 36 & 36 & 38 & 38 & 26 & 26 & 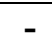 & - & 36 & 18 & 64 & 32 & تبوير الأراضي الزراعية \\
\hline
\end{tabular}

بقرية طاليا ذوي مستوى منخفض من تلوث المجاري

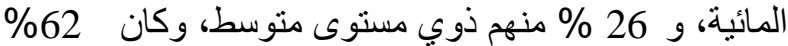

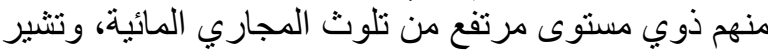

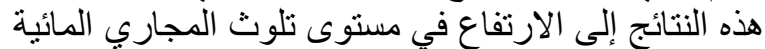

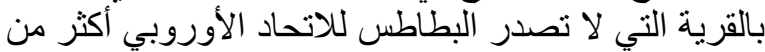

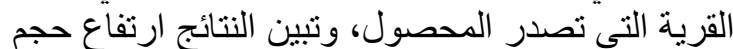
تلوث المجاري المائية في المستوى الأعلى في قرية فئن طاليا

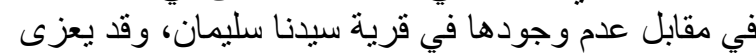

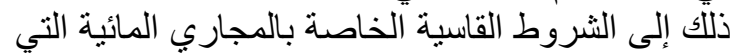

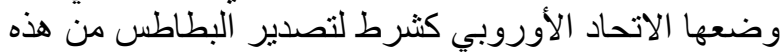

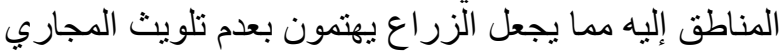

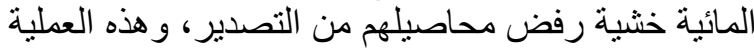

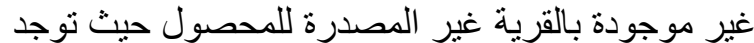
اللامبالاه في التعامل مع المجاري الإي المائية و هي أحد أسباب رفض الاتحاد الأوروبي استلام بطاطس مصرئ الإنية من هذه الإنه

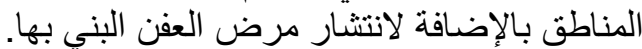

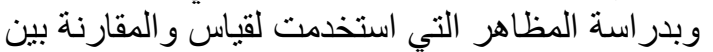

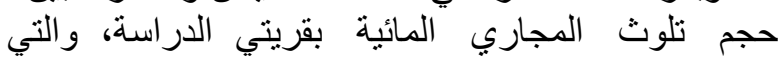

وبالنسبة لمؤشر تجريف الأراضي الزر اعية وهو مظهر الزئي

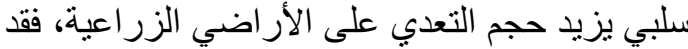

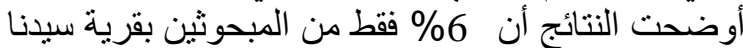

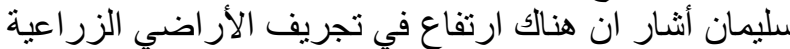

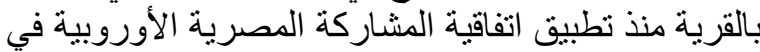

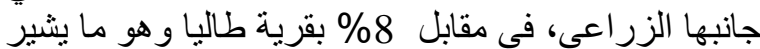
إلى ارتفاع هذا المؤشر بقرية طاليا أكثر من قرية طئ سيدانيا

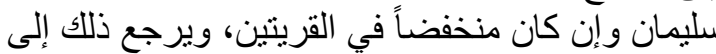

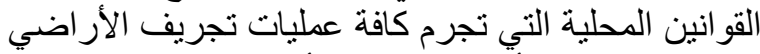
الزر اعية سواء بالأر اضي الجديدة أو القديمة القية.

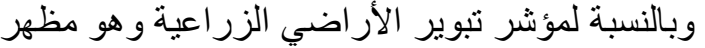

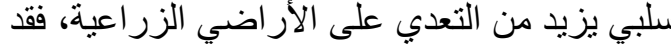

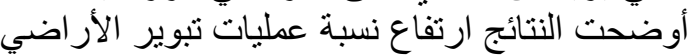

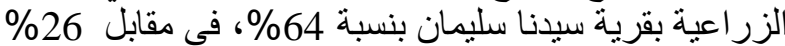
بقرية طاليا منذ تطبيق اتفاقية المشاركة المصرية المية الأوروبية

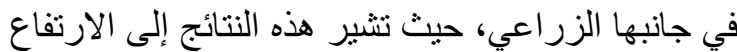

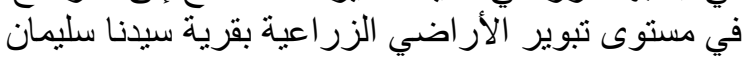

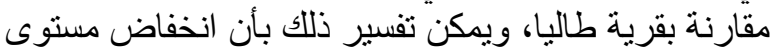


اتفاقية المشاركة المصرية الأوروبية في جانبها الزر اعي،

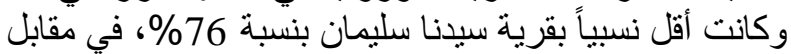

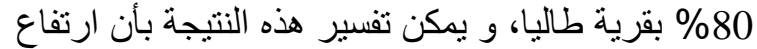

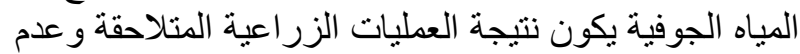

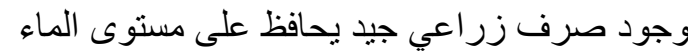

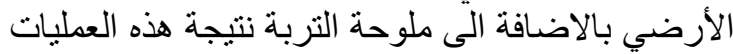

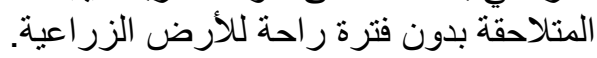

1-3-3-4 المحافظة على البيئة

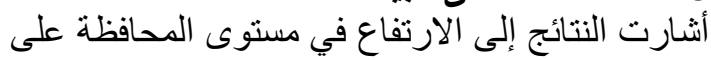

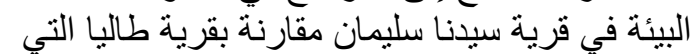

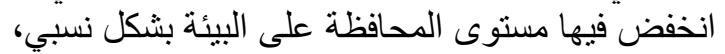

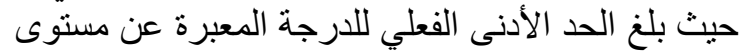

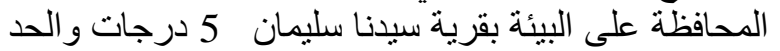

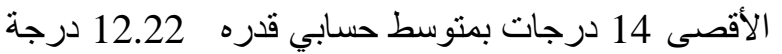

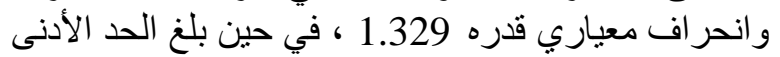

الفعلي للارجة المعبرة عن مستوى المحافظة على على البيئة الإني

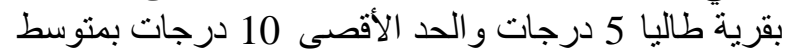
حسابي قدره 7.52 درجة و انحر اف معياري قدره 10 دراته 1.568.

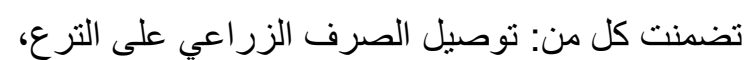

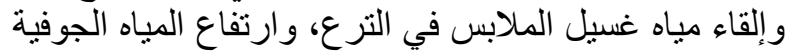

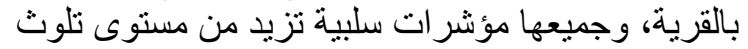

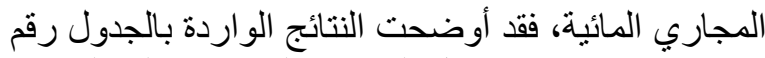

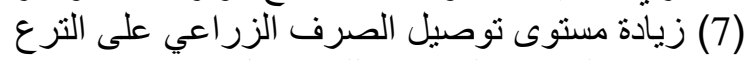

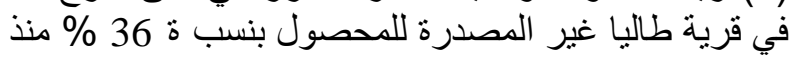

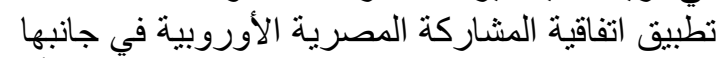

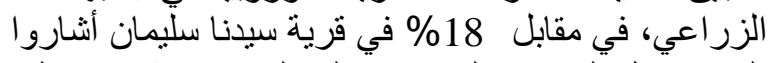

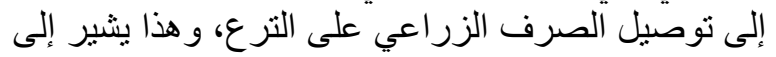

ارتفاع في هذا المؤشر بقرية طاليا مقارنة بقرية سيدنا

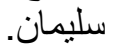

جدول (6): توزيع المبحوثين بقريتى الدراسة وفقا لمستوى تلوث المجاري المائية.

\begin{tabular}{|c|c|c|c|c|}
\hline \multicolumn{2}{|c|}{ قرية طاليا } & \multicolumn{2}{|c|}{ قرية سيدانـا } & \multirow{2}{*}{ المجنوى تلوث المائية } \\
\hline$\%$ & عدد & $\%$ & عدد & \\
\hline 12 & 12 & 56 & 28 & تلوث منخفض \\
\hline 26 & 26 & 44 & 22 & تلوث متوسط \\
\hline 62 & 62 & - & - & تلوث مرتفع \\
\hline 100 & 100 & 100 & 50 & الإجمالي \\
\hline
\end{tabular}

جدول (7) : توزيع المبحوثين بقريتى الدراسة وفقا لمظاهر قياس تلوث الأراضي الزراعية.

\begin{tabular}{|c|c|c|c|c|c|c|c|c|c|c|c|c|}
\hline \multicolumn{6}{|c|}{ قرية طاليا } & \multicolumn{6}{|c|}{ قرية سيدنا سليمان } & \multirow{3}{*}{ الأراضي الزراعية تلوثة } \\
\hline \multicolumn{2}{|c|}{ قل } & \multicolumn{2}{|c|}{ لـ لم يتغير } & \multicolumn{2}{|c|}{ زاد } & \multicolumn{2}{|c|}{ قل } & \multicolumn{2}{|c|}{ ل لم يتغير } & \multicolumn{2}{|c|}{ زاد } & \\
\hline$\%$ & عدد & $\%$ & عدد & $\%$ & عدد & $\%$ & عدد & $\%$ & 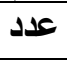 & $\%$ & عدد & \\
\hline - & - & 64 & 64 & 36 & 36 & 62 & 31 & 20 & 10 & 18 & 9 & توصيل الصرف الزراعي على الترع \\
\hline - & - & 44 & 44 & 56 & 56 & 50 & 25 & 32 & 16 & 18 & 9 & إلقاء مياه غسيل الملابس في الترع \\
\hline - & - & 20 & 20 & 80 & 80 & 12 & 6 & 12 & 6 & 76 & 38 & ارتفاع المياه الجوفية \\
\hline
\end{tabular}

وقد أظهرت نتائج الجدول رقم ( 8) عدم وجود أي من

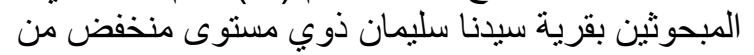

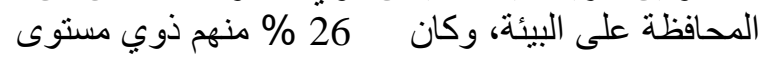
متوسط، و 74\% منهم ذوب الينة، وكان مستوى مرتفع من المحافظة

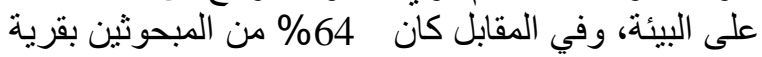

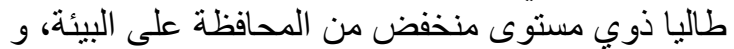

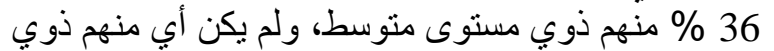
مستوى مرتفع من المحافظة على البيئة، وتثير هذئ التئه النتائج

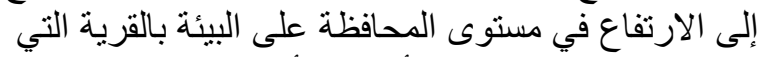

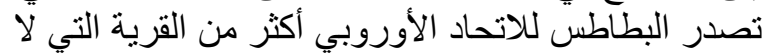

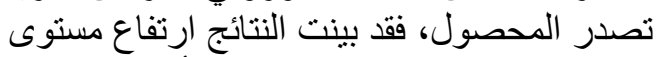
المحافظة على البيئة في المستوى الأعلى في قرية سيداع فئنا

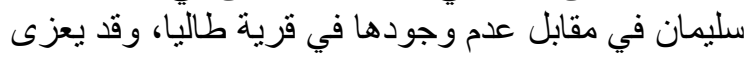

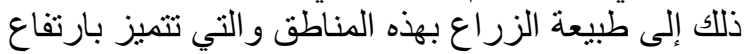

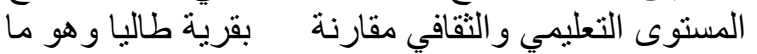
يجعلهم أكثر رعاية ومحافظة على البيئة.
وبالنسبة لمؤشر إلقاء مياه غسيل الملابس في الترع الزبر

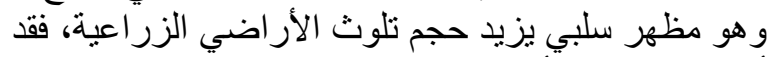

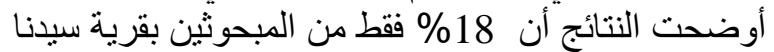
سليمان أنشاروا الي ان أن هناك ارتفاع في إلقاء مياه غسيل

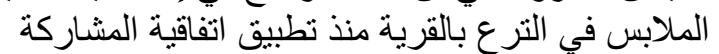

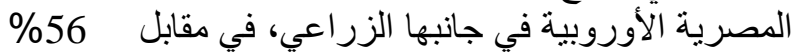
بقرية طاليا، وهو ما يشير إلى ارتفاع هذا الزئا المؤشر بقرية

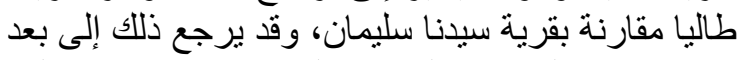

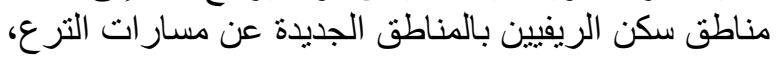

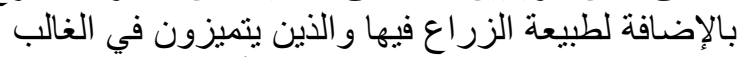

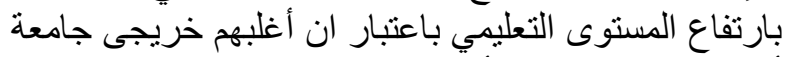

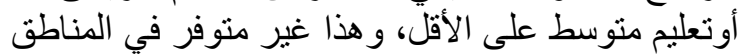
القديمة.

وبالنسبة لمؤشر ارتفاع المياه الجوفية وهو مظهر الزئ

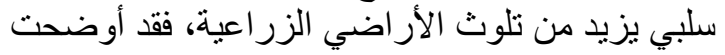
النتائج زيادة ارتفاع المياه الجوفية بقرى الدر اسة منذ تطبيق الزيق 
المؤشر ، وهو ما يثير إلى ارتفاع في هذا المؤشر بقرية

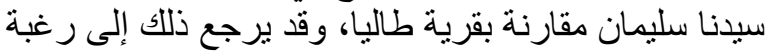

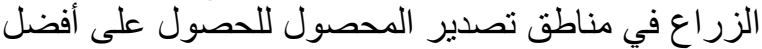

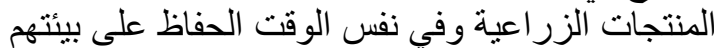

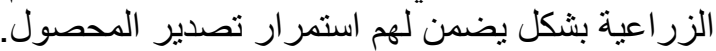

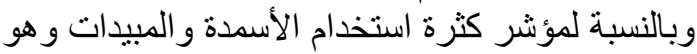

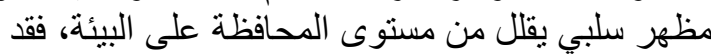

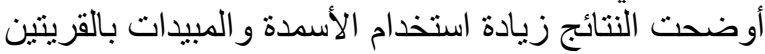

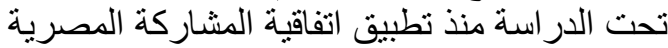

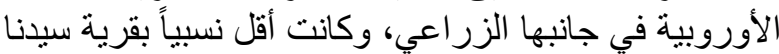

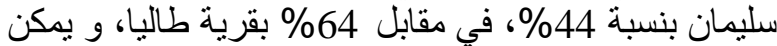
تفسير هذه النتيجة بأن ذلك يمثل أحد شروط تصدئ

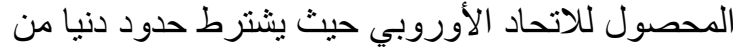

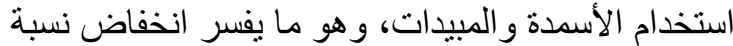

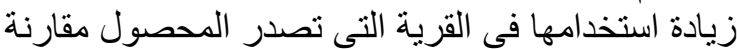
بالقرية التي لا تصدر المحصولّ المئل

وبالنسبة لمؤشر المعرفة بمسببات نلوث البيئة الريفية

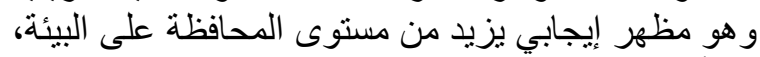

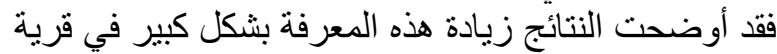

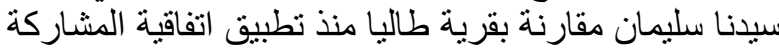

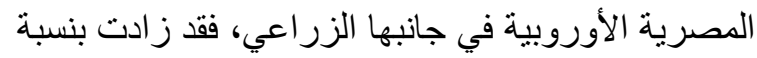

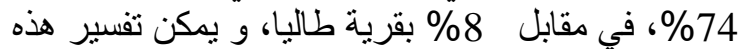

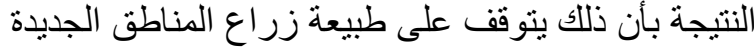

المميزة بارتفاع المستوى التعليمى و الثقافي بالإضيافة التئة

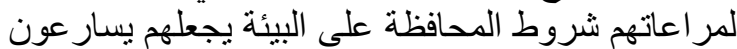

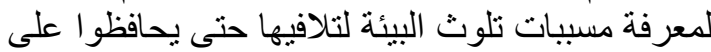
استمر ارية تصدير المحصول.

وبالنسبة لمؤشر استخدام نظم المكافحة الحيوية
جدول ( 8): توزيع المبحوثين بقريتى الدراسة وفقا لمستوى المحافظة على البيئة.

\begin{tabular}{|c|c|c|c|c|}
\hline \multicolumn{2}{|c|}{ قرية طاليا } & \multicolumn{2}{|c|}{ قرية سيدانـا } & \multirow[t]{2}{*}{ القرية } \\
\hline$\%$ & عدد & $\%$ & عدد & \\
\hline 64 & 64 & - & - & منخفض \\
\hline 36 & 36 & 26 & 13 & متوسط \\
\hline - & - & 74 & 37 & مرتفع \\
\hline 100 & 100 & 100 & 50 & الإجمالي \\
\hline
\end{tabular}

وبدراسة المظاهر التي استخدمت لقياس و المقارنة بين مستوى المحافظة على البيئة بقريتي الدر استة، و التي التي تضمنت كل من: المعرفة بأهمية المحافظة على المئية البيئة،

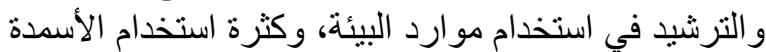

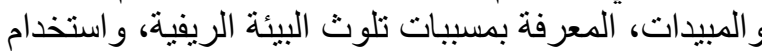

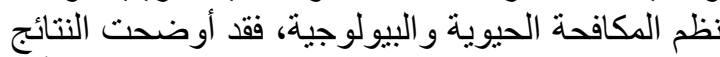
الواردة بالجدول رقم ( 9) زيادة مستوى المعرفة بأهمية المحافظة على البيئة في قرية سيدنا سليمان المصدرة اللمحصول بنسب ة 86 \% منذ تطبيق اتفاقية المشاركة

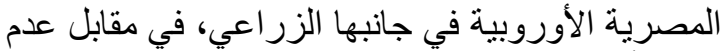

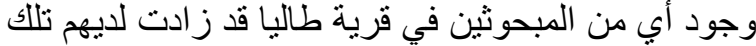

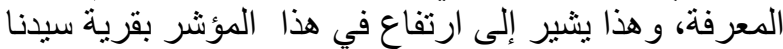

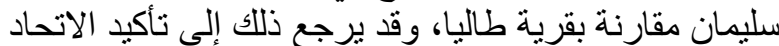

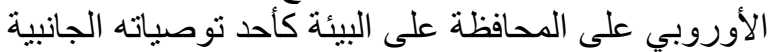
في مجال تصدير البطاطس ويأخذ ذلك الثنكال مختلفة أثناء

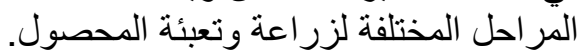

جدول (9): توزيع المبحوثين بقريتى الدراسة وفقا لمظاهر قياس المحافظة على البيئة .

\begin{tabular}{|c|c|c|c|c|c|c|c|c|c|c|c|c|}
\hline \multicolumn{6}{|c|}{ قرية طاليا } & \multicolumn{6}{|c|}{ قرية سيدنا سليمان } & \multirow{3}{*}{ مظاهر تلوث الأراضي } \\
\hline \multicolumn{2}{|c|}{ قَل } & \multicolumn{2}{|c|}{ ل لم يتغير } & \multicolumn{2}{|c|}{ زاد } & \multicolumn{2}{|c|}{ قَل } & \multicolumn{2}{|c|}{ ل لم يتغير } & \multicolumn{2}{|c|}{ زاد } & \\
\hline$\%$ & عدد & $\%$ & عدد & $\%$ & عدد & $\%$ & عدد & $\%$ & عدد & $\%$ & عدد & \\
\hline 76 & 76 & 24 & 24 & - & - & - & - & 14 & 7 & 86 & 43 & المعرفة بأهمية المحافظة على البيئة \\
\hline 76 & 76 & 24 & 24 & - & - & - & - & 38 & 19 & 62 & 31 & الترشيد في استخدام موارد البيئةً \\
\hline 24 & 24 & 12 & 12 & 64 & 64 & 6 & 3 & 50 & 25 & 44 & 22 & كثرة استخدام الأسمدة والمبيدات \\
\hline 28 & 28 & 64 & 64 & 8 & 8 & - & - & 26 & 13 & 74 & 37 & المعرفة بمسببات تلوث البيئة الريفية \\
\hline 36 & 36 & 64 & 64 & - & - & 12 & 6 & 38 & 19 & 50 & 25 & والبيولوجية نظم المكافحة الحيوية \\
\hline
\end{tabular}

و البيولوجية، وهو مظهر إيجابي يزيد من مستوى المحافظة

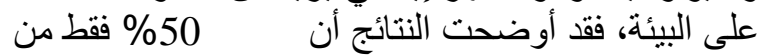

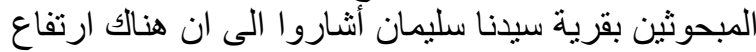

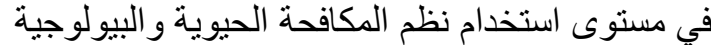

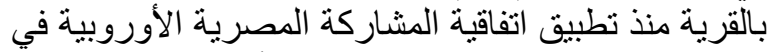

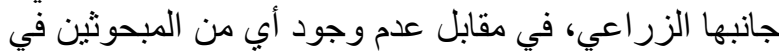

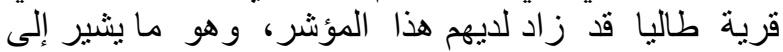

وبالنسبة لمؤشر الترشيد في استخدام موارد البيئة وهو

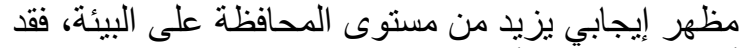

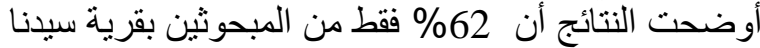

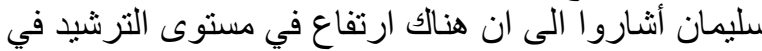

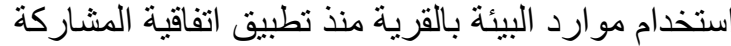

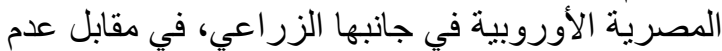
وجود أي من المبحوثين في قرية طُاليا قد زاد لديهر هذابل 
الميسرة بنسبة(28\%)، ومشكلة التعاقد مع الحياز ات الكبيرة

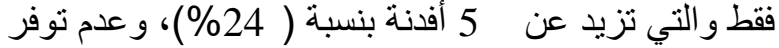

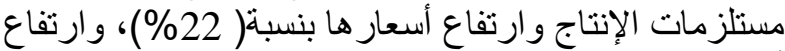

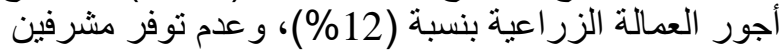

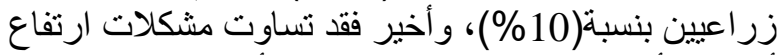

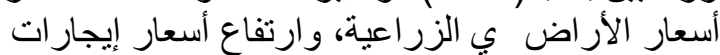

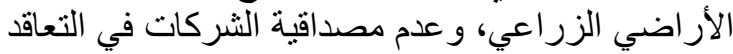

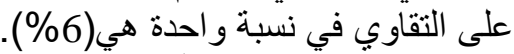
2-5 -5 مشكلات زراع قرية طاليا

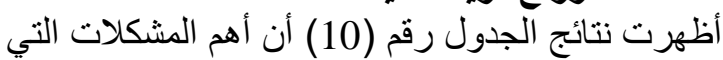

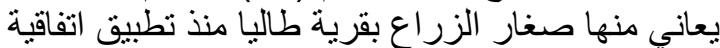

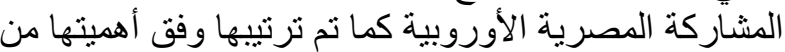

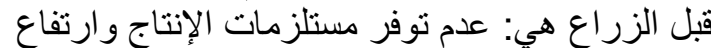

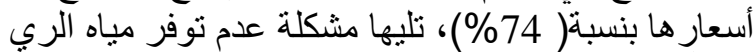

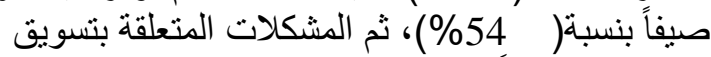

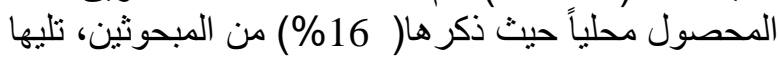

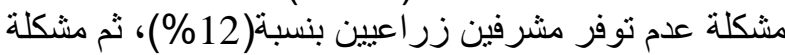

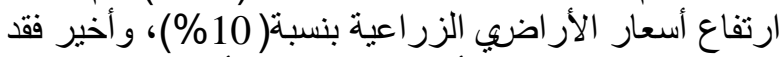

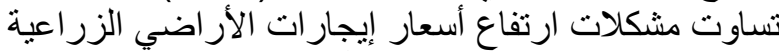

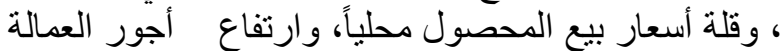

ارتفاع في هذا المؤشر بقرية سيدنا سليمان مقارنة بقرية

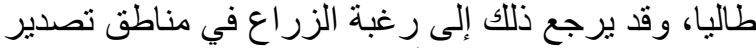

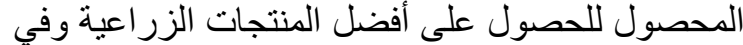

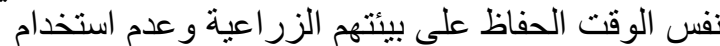

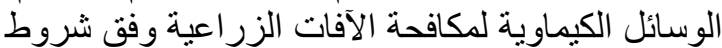

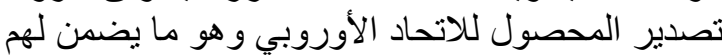

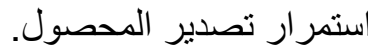

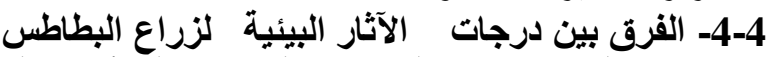
نتيجة تطبيق اتفاقية المشاركة المصرية الأوروبية البطاية

$$
\text { بقريتي الاراسة تبنة }
$$

ولدراسة الفروق بين درجات الآثار البيئية نتيجة

تطبيق اتفاقية المشاركة المصرية الأوروبية في جانبها الزر اعي في كل من القريتين المدروستين استخدم اختبار

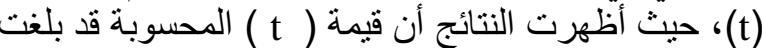

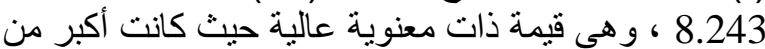

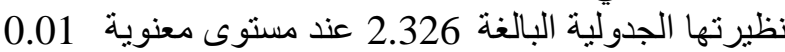
، و هذا يشير إلى وجود فرية فروق معنوية بين المبحوثين في القريتين من حيث درجة آثار البيئية نتيجة تطبيق لتين اتفاقية

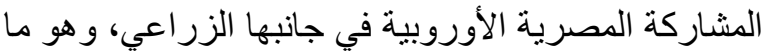
بعني وجود آثار بيئية سلبية نتيجة تطبيق هذه الاتفاقية.

جدول (10): المشكلات التي تواجه صغار الزراع بقريتي الاراسة منذ تطبيق اتفاقية المشاركة المصرية الأوروبية.

\begin{tabular}{|c|c|c|c|c|c|c|}
\hline$\%$ & 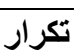 & مشكلات قرية طاليا & $\%$ & 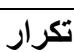 & مشكلات قرية سيدنا سليمان & 5 \\
\hline 74 & 74 & أسعار ها ها مستلزمات الإنتاج وارتفاع & 52 & 26 & عدم وجود فرص تسويق للمحصول محلياً & 1 \\
\hline 54 & 54 & عدم توفر مياه الري صيفاً & 36 & 18 & قلة أسعار تصدير المحصول. & 2 \\
\hline 16 & 16 & عدم وجود منافذ لتسويق المحصول محلياً & 34 & 17 & عدم توفر مياه الري صيفاً. & 3 \\
\hline 12 & 12 & عدم توفر مشرفين زر اعيين & 28 & 14 & عدم توفر القروض الميسرة. & 4 \\
\hline 10 & 10 & ارتفاع أسعار الأر اضي الزراعية & 24 & 12 & أفذنة. & 5 \\
\hline 8 & 8 & قلة أسعار بيع المحصول محلياً & 22 & 11 & عدم توفر مستلزمات الإنتاج وارتفاع أسعارها. & 6 \\
\hline 8 & 8 & ارتفاع أسعار إيجار ات الأر اضي الزر اعية & 12 & 6 & ارتفاع أجور العمالة الزر اعية. & 7 \\
\hline \multirow[t]{4}{*}{8} & 8 & ارتفاع أجور العمالة الزراعية & $\mathbf{1 0}$ & 5 & عدم توفر مشرفين زر اعيين. & 8 \\
\hline & & & 6 & 3 & ارتفاع أسعار الأر اضي الزراعية. & 9 \\
\hline & & & 6 & 3 & ارتفاع أسعار إيجار ات الأر اضي الزر اعي. & 10 \\
\hline & & & 6 & 3 & عدم مصداقية الثركات في التعاقد على التّقاوي. & 11 \\
\hline
\end{tabular}

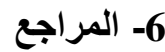

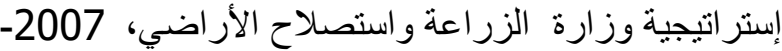

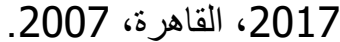

الحجر الزراعي المصري ، بيانات زراعة زاعة وتصدير

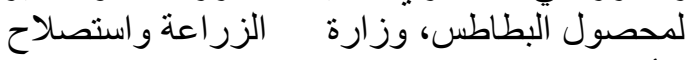

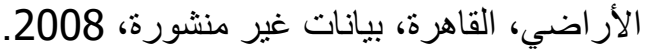

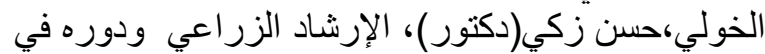
تطوير الريف، دار الكتب الجامعية، الإسكندرية، 1977

الثافعي ، عماد مختار (2000). الإرشاد الزئة الزراعي

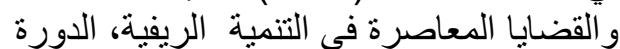
التدرييية عن المناهج ألجديدة في التنمية الريفية، كلية النورة
5- المشكلات التي تواجه صغار الزراع نتيجة تطبيق بنود

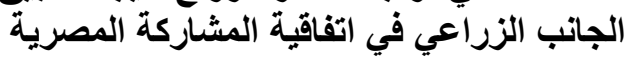
1-5- مشكلات زراع قرية سيدنا سليمان أظهرت نتائج الجدول رقم ( 10 10) أن أهم المشكلات

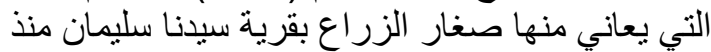

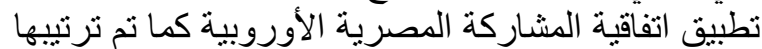

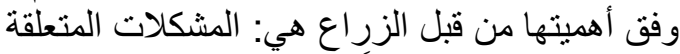

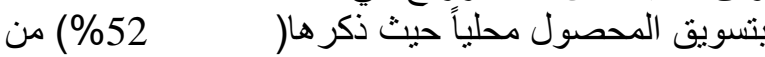

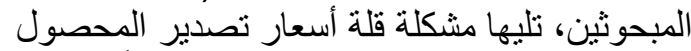

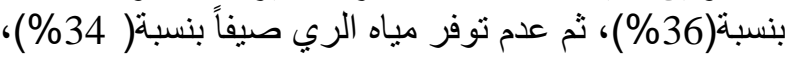

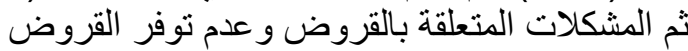




\section{6- REFERENCES}

Pottier J. (2004). Farmer experimentation and agricultural extension, beyond farmer first, rural peoples knowledge agricultural research and extension practice. edited by Jan Scones and John Thompson, with a foreword by Robert Chambers ,intermediate technology publications 1994.

Scarborough V., Killough D., Johnson A. and John F. (1997). Farmer- led Extension, ,intermediate technology publications on behalf of the overseas development institute

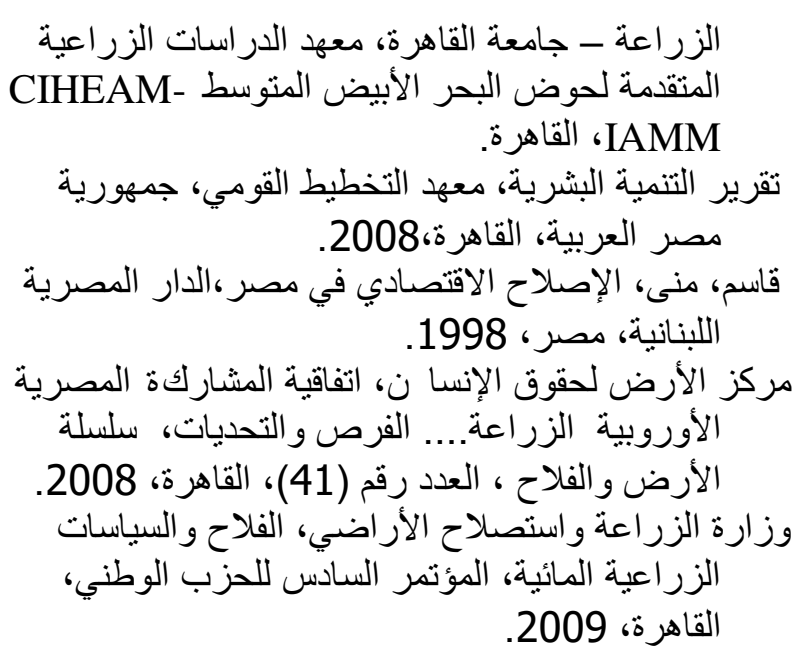

